\title{
Lactobacillus GG reduced diarrhoea incidence in children treated with antibiotics
}

Vanderhoof JA, Whitney DB, Antonson DL, et al. Lactobacillus GG in the prevention of antibiotic-associated diarrhea in children.J Pediatr 1999 Nov;135:564-8.

\section{QUESTION: In children being treated with antibiotics, does co-administration of Lactobacillus GG (LGG) reduce the incidence of diarrhoea?}

\section{Design}

Randomised (allocation concealed*), blinded (clinicians, patients, and outcome assessors),* placebo controlled trial with 10 day follow up.

\section{Setting}

Primary care paediatric practice in Rapid City, South Dakota, United States.

\section{Patients}

202 children between 6 months and 10 years of age who had an acute infection of the upper or lower respiratory tract, urinary tract, soft tissues, or skin and were prescribed a 10 day course of antibiotics. Exclusion criteria were chronic disease, serious acute infection, or diarrhoea at the start of antibiotic administration. 188 children (93\%) (median age $4 \mathrm{y}, 55 \%$ girls) completed the study.

\section{Intervention}

Children were allocated to LGG (CAG Functional Foods, Omaha, NE, USA) $(\mathrm{n}=93)$ or placebo $(\mathrm{n}=95)$. Children who weighed $<12 \mathrm{~kg}$ received 1 capsule $(10$ billion colony forming units of live LGG) daily with meals and those $\geq 12 \mathrm{~kg}$ received 2 capsules (20 billion colony forming units).

\section{Main outcome measures}

Incidence of diarrhoea ( $\geq 2$ liquid stools/d on $\geq 2$ occasions), stool consistency (rated on an 8 point scale: $1=$ watery, $4=$ loose and soft, and $8=$ hard and dry), and stool frequency.

\section{Main results}

Fewer children who received LGG had diarrhoea than did those who received placebo $\{\mathrm{p}<0.001\} \uparrow$ (table). The mean duration of diarrhoea was slightly shorter in the LGG group than in the placebo group (4.7 $v 5.9 \mathrm{~d}$, $\mathrm{p}=0.05)$. Fewer children who received LGG had a stool consistency score $<4$ than did those who received placebo $(\mathrm{p}<0.001)$ (table). By day 10, stool frequency was lower in the LGG group than in the placebo group (mean number of stools/d $1.4 v 2.0, \mathrm{p}<0.02$ ).

\section{Conclusion}

In children being treated with antibiotics, the coadministration of Lactobacillus $G G$ reduced the incidence and duration of diarrhoea, watery or soft stool consistency, and stool frequency.

*See glossary.

tp Value calculated from data in article.

\section{COMMENTARY}

Diarrhoea is a common side effect of oral antibiotic treatment. Probiotics (micro-organisms that survive passage through the gut and have a beneficial effect on the host ${ }^{1}$ ) have been used to reduce the incidence of antibioticassociated diarrhoea or the duration of diarrhoea with rotavirus infection. ${ }^{2}$ The study by Vanderhoof $e t$ al examines the effect of probiotics on antibiotic associated diarrhoea in children and quantifies its benefits. It thus adds to the existing fund of knowledge.

The study was done in the US among outpatients who were 6 months to 10 years of age. The children were assessed every third day for frequency and consistency of stools and occurrence of other gastrointestinal symptoms. Diarrhoea is usually defined as $>3$ loose, watery stools per day. ${ }^{3}$ The authors, however, used a cut point of $>2$ for defining diarrhoea and reported that fewer children in the LGG group than in the placebo group had diarrhoea. More children in the placebo group had increased stool frequency and loose stools at the end of the study. However, none of the patients discontinued antibiotic treatment because of changes in stool consistency or frequency.

The perceived benefits of LGG from the perspective of the patient (or parent) were not assessed in the study. Therefore, the payer must decide whether to spend extra money for the concomitant administration of LGG and oral antibiotic treatment to have about 1 less day with $>2$ loose bowel movements.

Shally Awasthi, MD, MSc King George's Medical College Lucknow, India

1 de Roos NM, Katan MB. Effects of probiotic bacteria on diarrhoea, lipid metabolism, and carcinogenesis: a review of papers published between 1988 and 1998. Am J Clin Nutr 2000;71:405-11.

2 Pant AR, Graham SM, Allen SJ, et al. Lactobacillus GG and acute diarrhoea in young children in the tropics. J Trop Pediatr 1996;42:162-5.

3 World Health Organisation. The treatment of diarrhoea. A manual for physicians and other senior health workers. WHO/ $\mathrm{CDR} / 95.3: 2$.

http://www.who.int/chd/publications/cdd/textrev4.htm.
Lactobacillus $G G(L G G)$ v placebo for diarrhoea in children receiving 10 days of antibioticsł

\begin{tabular}{lllll} 
Outcomes & LGG & Placebo & RRR (95\% Cl) & NNT (Cl) \\
Diarrhoea & $8 \%$ & $26 \%$ & $71 \%(39$ to 87$)$ & 6 (4 to 13) \\
\hline Stool consistency score $<4 \S$ & $17 \%$ & $48 \%$ & $64 \%(43$ to 78$)$ & 4 (3 to 6) \\
\hline †Abbreviations defined in glossary; RRR, NNT, and Cl calculated from data in article. \\
§Stool consistency score <4 means that stool consistency ranged from loose and soft to watery.
\end{tabular}

